EXTENDED REPORT

\title{
Health services experiences of parents of recently diagnosed visually impaired children
}

\author{
J S Rahi, I Manaras, H Tuomainen, G Lewando Hundt
}

Br J Ophthalmol 2005;89:213-218. doi: 10.1136/bjo.2004.051409

See end of article for authors' affiliations .....................

Correspondence to: Jugnoo Rahi, Centre for Paediatric Epidemiology and Biostatistics, Institute of Child Health, 30 Guilford Street, London WCIN 1EH, UK; j.rahi@ich.ud. ac.uk

Accepted for publication 21 July 2004
Aim: To investigate the health service experiences and needs of parents in the period around diagnosis of ophthalmic disorders in their children.

Methods: Parents of children newly diagnosed with visual impairment and/or ophthalmic disorders at a tertiary level hospital in London participated in a questionnaire survey, using standard instruments, followed by in-depth individual interviews, to elicit their views about the processes of care, their overall level of satisfaction, and their unmet needs.

Results: $67 \%$ (147) of eligible families (135 mothers, 76 fathers) participated. Overall satisfaction with care was high, being greater among parents of children with milder visual loss or isolated ophthalmic disorders than those with more severe visual loss or multiple impairments. Nevertheless, parents' reported greatest need was the provision of general information, including about their child's ophthalmic disorder and educational and social services and support. Mothers reported greater information needs than fathers, as did white parents compared to those from ethnic minorities. White parents also regarded the processes of care to be less comprehensive and coordinated, as well as less enabling, than did parents from ethnic minorities.

Conclusions: Although parents reported high overall satisfaction with services, improving the medium, content, and scope of general information provided by professionals to parents of visually impaired children emerges as a priority. Equitable planning and provision of health services for families of children with visual impairment needs to take into account that informational and other needs vary by whether the parent is the primary carer or not and their ethnicity, as well as by the severity and complexity of their child's visual loss.
V isual loss in childhood has lifelong and far reaching consequences for the affected child and family, and society in general. ${ }^{1}$ The period around diagnosis is critical for parents to enable them to understand and accept their child's visual impairment and identify her/his specific needs, as a foundation for their role as effective advocates for their child. ${ }^{2}{ }^{3}$ In general, health services have a greater role at this time than they do later, when educational, social, and other professional sectors may predominate. The importance of involving "users" in the planning of health services ${ }^{4}$ and the need for services for children with disability to be family centred $^{5}$ are well recognised. However, there has been limited study of the views and experiences of parents of visually impaired children with which to inform service provision. We report, from a study combining quantitative and qualitative approaches, the health service experiences of parents of children recently diagnosed with ophthalmic disorders at a tertiary level centre in Britain.

\section{METHODS}

Between 2000 and 2002 we undertook a postal questionnaire survey followed by in-depth individual interviews of parents during the 12-18 months following new diagnosis of ophthalmic disorders in their children, as described previously. ${ }^{6}$ The families of all children newly diagnosed as visually impaired, together with a random sample of those newly diagnosed with milder visual loss, during one of two 12 month periods (August 1999 to July 2000 and December 2000 to November 2001, respectively) in the Department of Ophthalmology, Great Ormond Street Hospital (GOS), London, were eligible. Children previously diagnosed but attending GOS for the first time for confirmatory investigations or for treatment which could not be undertaken elsewhere were not eligible.

The family doctors of the children eligible for the study were informed and asked for any reasons that the families should not be contacted. The parents for whom there were no reasons to preclude contact were invited to take part and were sent an information sheet, a consent form, a form to decline participation, and reply paid envelopes. Copies of each questionnaire instrument were provided for each parent.

The main instrument was the measure of processes of care (MPOC), a validated 56 item English language self complete questionnaire developed ${ }^{7}$ and used $^{9-12}$ to evaluate parental experiences of the degree to which health services for a range of childhood disorders are family centred. ${ }^{13}$ It comprises five analytically determined subscales assessing the processes rather than content of care (box 1). The Client Satisfaction Questionnaire $^{14}$ is an English language self complete instrument used previously to assess parental satisfaction with paediatric services, ${ }^{15}$ including in conjunction with the MPOC. ${ }^{7}$ The short form, comprising three items, was used to elicit overall parental satisfaction or dissatisfaction with services in the preceding year (box 1).

Detailed socioeconomic and demographic information, including self reported ethnic group, ${ }^{16}$ education, ${ }^{17}$ occupation, ${ }^{18}$ home and car ownership ${ }^{17}$ (using standard taxonomies of the Office for National Statistics) was also sought by questionnaire, together with family structure and history of

Abbreviations: GOS, Great Ormond Street Hospital; MPOC, measure of processes of care 
Box 1 Measure of processes of care $(\mathrm{MPOC})^{7}$ subscales

1. "Providing general information" focuses on activities related to meeting parents' general information needs-for example, about their child's disorder or education or social services.

2. "Providing specific information about the child" relates to information provision specific to a given child-for example, about the timing and purpose of clinical investigations or treatments.

3. "Enabling and partnership" assesses the degree to which parental input is elicited and the extent of parental involvement in decision making about the care of their child.

4. "Respective and supportive care" describes the extent to which parents are treated respectfully as individuals and equals.

5. "Coordinated and comprehensive care for the child and family" encompasses the holistic needs of the family and the extent to which services are continuous and consistent over time, settings, and people.

\section{Client satisfaction questionnaire (short form) items}

1. To what extent has the care provided met your needs?

2. Has the care you have received helped you deal better with your child's problems?

3. In an overall, general sense, how satisfied are you with the care you have received at the hospital?

visual impairment. Clinical details about the child, including severity of visual loss and presence of other non-ophthalmic impairments were sought from the clinical case notes. Quantitative data were entered into a specifically designed database (SPSS v1 1, 2001, SPSS Inc, Chicago, IL, USA). Nonresponding parents were prompted twice over the ensuing month, firstly by telephone and then by posting a second study pack.

To promote adequate representation of ethnic minority or socioeconomically deprived families and also fathers, all potentially underascertained in research about families of children with disability, ${ }^{19}$ as well as to ensure a range of severity and complexity (isolated versus multiple) of visual impairment, a stratified subsample of parents returning completed questionnaires was invited to take part in personal interviews. All were conducted in the family home at times chosen by the parents and by the same investigator. They were semistructured and employed a topic guide constructed from review of the literature, discussions with relevant professionals, and two pilot interviews. All interviews were taped, with permission, and transcribed verbatim. Checked transcripts were entered, coded, and analysed using a qualitative data analysis program (NVivo QSR 1.3, 2000, QSR International Pty Ltd).

Data were handled in accordance with current guidance on confidentiality. The Institute of Child Health/Great Ormond Street Hospital local research ethics committee approved the study, which conformed to the tenets of the Declaration of Helsinki.

\section{Analysis}

Scores for the questionnaires were derived according to guidance on their use. Internal reliabilities were assessed using Cronbach's alpha coefficient..$^{20}$ Domain specific MPOC and Client Satisfaction Questionnaire scores for each respondent were used to derive the summary scores, having examined skewness and kurtosis indices. ${ }^{21}$ Variations in scores were examined according to sociodemographic characteristics of the respondent/family and clinical characteristics of their child considered, a priori, to be important. The strength and direction of associations were quantified using Pearson's correlation coefficient ${ }^{21}$ and differences between groups were examined using $t$ tests or $\mathrm{F}$ tests. ${ }^{21}$

Following descriptive coding, using a framework developed through close analysis of interview transcripts, joint higher order analysis of the qualitative data was carried out on topics categorised thematically in nodes consistent with the MPOC subscales.

The specific impact of a new key worker support and liaison service (GOS Ophthalmology "Community Link Team"), implemented during the study period, on parents' experiences will be reported in detail separately.

\section{RESULTS}

The parents of 147 children (67\% of 221 invited) participated in the questionnaire survey, comprising 135 mothers and 76 fathers. The parents of 48 of these children were interviewed (23 couples, 23 mothers only, two fathers only). The sociodemographic and clinical characteristics of participants are shown in table 1. Parents from ethnic minority groups, those whose first language was not English, and those from more socioeconomically deprived were slightly underrepresented among participants, as reported elsewhere. ${ }^{6}$

The five subscales of the MPOC showed good internal consistency (Cronbach's alpha range 0.87 to 0.93 ) as did the Client Satisfaction Questionnaire (0.85). Individual scores were sufficiently normally distributed to enable mean scores for both instruments to be derived. The highest MPOC domain specific score was for "respectful and supportive care" and the lowest for "general information." The mean Satisfaction score was high (table 2). Statistically significant associations $(\mathrm{p}<0.05)$ between MPOC and "satisfaction" scores and parents' sex and ethnic group, as well as level of the child's visual loss and whether it was isolated or not, are summarised in table 2 . We found no significant associations between these scores and child's age; parents' age, educational attainment, or occupation; families' material deprivation, car ownership, housing tenure or structure (one or two parent). However, the size of the study sample may have limited the ability to detect true differences for some variables.

There were significant positive correlations between MPOC subscale scores and satisfaction scores suggesting that, overall, the more parents viewed care as being family centred, the greater their satisfaction (table 3). Notably, both "general information" and "specific information" were the least well correlated with satisfaction, which supports that meeting information needs may be less important than other processes of care in achieving family centredness, and thus, parental satisfaction.

The major needs expressed in the interviews by parents regarding services at GOS are summarised in box 2 . The pathways to tertiary care for most of these families with children with rare conditions had involved numerous consultations before their first appointment at GOS (18/48 having seen four or more health professionals) and many parents had endured uncertainty over a prolonged period of time. Most (41) families reported receiving only verbal information about their child's condition before attending 


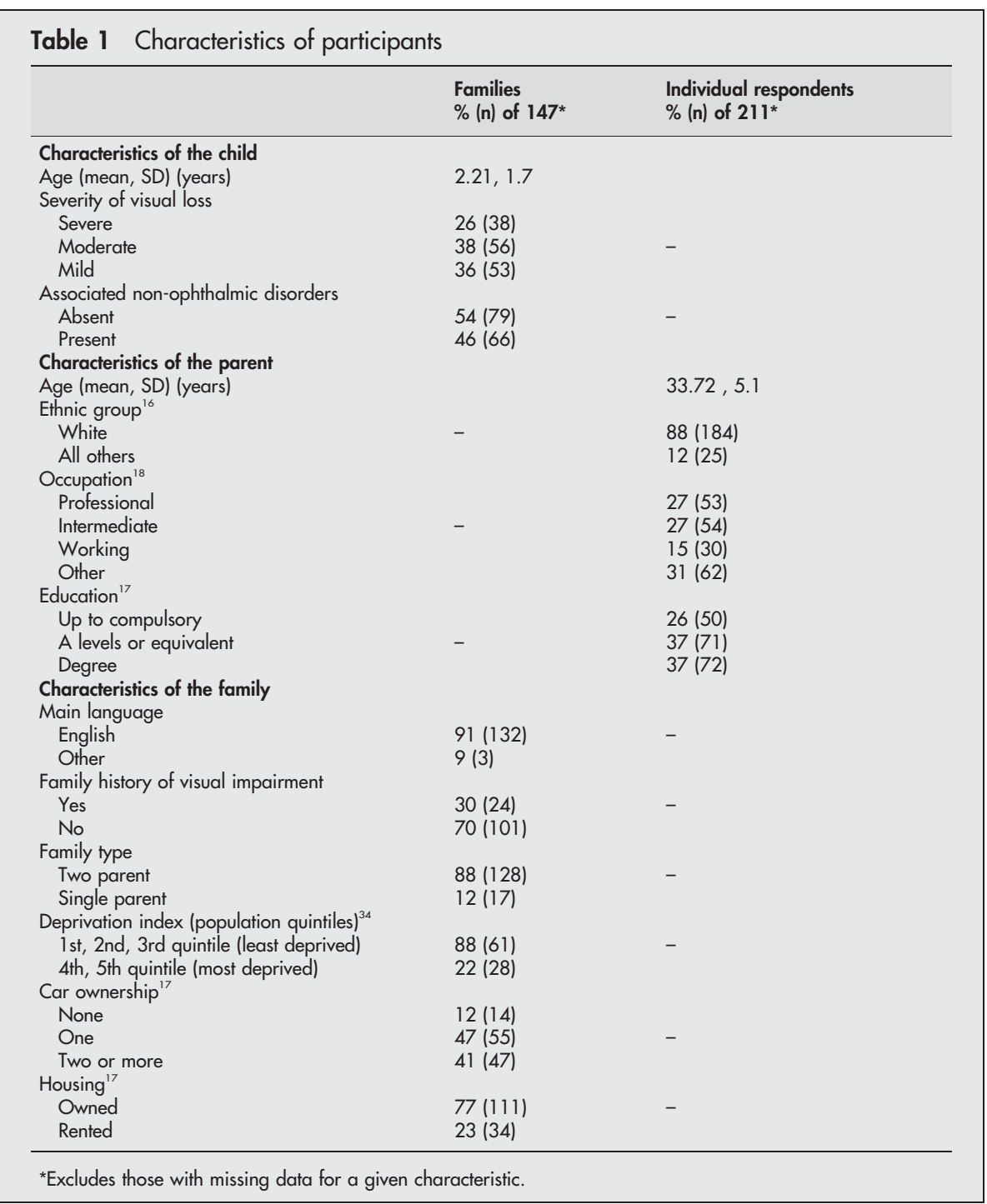

GOS. After attending GOS, most families (40) reported the consultant ophthalmologist to be their main (and in 17 their sole) source of information with 23 also using the internet and seven citing charities for the visually impaired.

\section{Quote 1}

- Father: "One thing I would say is that it has been down to my wife to find out about a lot of what is available. ...in the first six to eight months you know no one comes up to you and says "You've got this; you can do this, you can do that, you can do the other..." (13A)

The interviews supported that the observed differences between mothers' and fathers' MPOC scores for information reflected the greater information needs of the primary carer responsible for accessing and using services, who in most cases was the mother, even if the father attended all major medical appointments.

\section{Quote 2}

- Mother: "Your life is constantly one great big battle for your children you know. Having to fight for services. I talk to other females who are mums in the same situation and you always think you want to know more because you're with them, or you notice them more. And you notice things much more, even more aware of the other special needs and things like that. I'm always thinking ahead you know. And I suppose because he sees him in the evenings or like during the appointment times. It doesn't always, I think, probably hit at the same level."

- Father: "You could be right"

- Mother: "Yeah I mean my friends have found similar things with their husbands as well, the concerns are different from what a mother's concerns are."

- Father: "I am sure it would have been the same if I had been with him and you had been going to work."

- Mother: "I mean just relating to what my friends at the opportunity playgroup feel. Whenever they go for an appointment, it's always them asking the questions and you know they are there most of the time; the husbands some of the times can't get the time off work." (28A)

The qualitative data also supported that parents of children with less severe disorders were more satisfied with care than those with more severe conditions-most of their children had received treatment which had improved their vision and, having attended clinic several times, they generally realised that many other children attending the hospital were much worse off than their own. 


\begin{tabular}{|c|c|c|c|c|c|c|}
\hline \multirow[b]{2}{*}{ Scores (mean) } & \multicolumn{5}{|c|}{ Measure of processes of care } & \multirow[b]{2}{*}{$\begin{array}{l}\text { Satisfaction } \\
\text { (range 0-5) }\end{array}$} \\
\hline & $\begin{array}{l}\text { General information } \\
\text { (range } 0-7 \text { ) }\end{array}$ & $\begin{array}{l}\text { Specific } \\
\text { information } \\
\text { (range 0-7) }\end{array}$ & $\begin{array}{l}\text { Respectful and } \\
\text { supportive care } \\
\text { (range 0-7) }\end{array}$ & $\begin{array}{l}\text { Coordinated and } \\
\text { comprehensive care } \\
\text { (range 0-7) }\end{array}$ & $\begin{array}{l}\text { Enabling and } \\
\text { partnership } \\
\text { (range 0-7) }\end{array}$ & \\
\hline \multicolumn{7}{|l|}{ ALL (211) } \\
\hline Mean & 3.07 & 4.90 & 5.14 & 4.25 & 4.84 & 4.09 \\
\hline SD & 1.75 & 2.80 & 1.29 & 1.41 & 1.41 & 0.76 \\
\hline Min & 0 & 0 & 1.06 & .39 & 1.30 & 1.67 \\
\hline Max & 7 & 7 & 7 & 6.61 & 7 & 5 \\
\hline \multicolumn{7}{|l|}{ Sex } \\
\hline Women & 2.83 & 4.53 & 5.12 & 4.18 & 4.77 & 4.02 \\
\hline Men & 3.46 & 5.54 & 5.17 & 4.34 & 4.95 & 4.21 \\
\hline$t$ test & -2.50 & -2.50 & -0.23 & -0.76 & -0.86 & -1.73 \\
\hline $\mathrm{p}$ & 0.013 & 0.013 & 0.82 & 0.45 & 0.39 & 0.09 \\
\hline \multicolumn{7}{|l|}{ Ethnic group } \\
\hline White & 2.92 & 4.67 & 5.12 & 4.15 & 4.77 & 4.11 \\
\hline Other & 4.07 & 6.53 & 5.36 & 4.94 & 5.46 & 3.94 \\
\hline$t$ test & -3.11 & -3.11 & $0-.82$ & -2.58 & -2.30 & 0.99 \\
\hline $\mathrm{p}$ & 0.002 & 0.002 & 0.41 & 0.01 & 0.02 & 0.32 \\
\hline \multicolumn{7}{|c|}{ Severity of visual loss } \\
\hline Mild & 2.75 & 4.40 & 5.18 & 4.34 & 5.00 & 4.31 \\
\hline Moderate & 3.28 & 5.25 & 5.21 & 4.18 & 4.80 & 4.04 \\
\hline Severe & 3.18 & 5.09 & 4.96 & 4.17 & 4.68 & 3.87 \\
\hline F test & 1.89 & 1.88 & 0.65 & 0.29 & 0.81 & 5.83 \\
\hline & 0.15 & 0.15 & 0.52 & 0.75 & 0.45 & 0.003 \\
\hline \multicolumn{7}{|c|}{ Non-ophthalmic disorders } \\
\hline Absent & 3.15 & 5.03 & 5.21 & 4.34 & 4.94 & 4.20 \\
\hline Present & 2.99 & 4.78 & 5.21 & 4.09 & 4.69 & 3.94 \\
\hline$t$ test & 0.65 & 0.64 & 1.04 & 1.20 & 1.25 & 2.43 \\
\hline p & 0.52 & 0.52 & 0.29 & 0.23 & 0.21 & 0.02 \\
\hline
\end{tabular}

\section{Quote 3}

- Mother: "I think also ... going somewhere like that really puts your own case in perspective. You know if you were going to a clinic where $G$ was one of the worst, you would probably be a lot more worried even throughout the treatment but when you're going to a clinic where clearly she is one of the better or lesser less affected cases..." (21A)

Most children with severe visual loss (9/13) had untreatable disorders and also other non-ophthalmic impairments. For their families, it was clear that there was no remedy available at that time, and that the longer term future was also uncertain, in terms of levels of vision and any possible treatment. Many parents of children with multiple impairments indicated that the non-ophthalmic problems were their greatest concern, even if their child had very poor eyesight; others explained how it was sometimes difficult to distinguish between problems.

\section{Quote 4}

- Mother: "The eyes, his eyes are kind of on the back burner. ... I suppose it's because he's got a list of things, it's not just his eyes. You know he wants everything else to be sorted out." (33B)
- Mother: "It's all linked together really. She's got a problem with walking, I mean especially when we're outside and you've got different levels of pavement. She falls over quite often out there she does... she doesn't like being put in her pushchair, she'd rather walk, she's very determined. But she'll fall over quite a lot and sometimes you think well is it because of her eyes or is it because of her foot?" (27A)

\section{DISCUSSION}

The parents in this study were satisfied with the services they had experienced in the year or so following diagnosis of visual impairment or ophthalmic disease in their children at a tertiary level centre. Nevertheless, a number of areas for improvement in the processes of care are identified. The most important is provision of general information, including about the disorder itself, social services, support networks, and education. Parents were less critical about the provision of specific information about their child (for example, details of specific assessments and treatment), about the attainment of care that is coordinated and comprehensive, as well as respectful and supportive, and promotes parental enabling and partnership. There were important variations in their views about services and their overall satisfaction according

Table 3 Pearson's correlation matrix between MPOC domains ${ }^{7}$ and satisfaction ${ }^{14}$

\begin{tabular}{lllllll}
\hline & 1 & 2 & 3 & 4 & 5 & 6 \\
\hline General information & & & & & \\
Specific information & 0.98 & - & & & & \\
Respectful and supportive care & 0.46 & 0.46 & - & & \\
Coordinated and comprehensive care & 0.57 & 0.57 & 0.77 & - & \multicolumn{2}{l}{} \\
Enabling and partnership & 0.53 & 0.53 & 0.84 & 0.89 & - \\
Satisfaction & 0.28 & 0.23 & 0.63 & 0.56 & 0.63 & - \\
\hline
\end{tabular}


Box 2 Summary of main needs reported by parents

- More written information needed about the vision problem, treatment, and prognosis

- More written information needed about accessing services and benefits

- Parents of children with multiple impairments have complex informational needs

- Value of meeting with families with children with similar problems

- Main carer (usually mother) has greater information needs

- Ethnic minority families are more dependent on health professionals (especially the consultant ophthalmologist) for information

- More time needed with consultants

- Better administrative services/support required

- More emotional support needed from health professionals

- Importance of coordination of appointments between different departments/specialties

- Better liaison required with community based services

to their role as primary or secondary care and their ethnicity, as well by the level of visual loss in their child and whether it was isolated or part of a complex of impairments.

Participation in our study was comparable to other studies of parental experiences of services for children with disability $^{9} 0^{12}{ }^{13}$ and the diverse experiences of parents were elicited systematically and in detail by combining robust questionnaire instruments with in-depth personal interviews. Thus, we suggest the findings of this study provide a richer picture than has previously been available of the health services experiences of parents at the critical time around the diagnosis of visual impairment in their child. However, that parents from socioeconomically deprived groups and ethnic minorities were slightly under-represented, as previously reported, ${ }^{6}$ does have some implications for interpretation of parental experiences, as discussed below.

Provision of health services for children with visual impairment poses some challenges which may not pertain to other childhood impairments. Visual impairment is uncommon, affecting $1-2$ per 1000 children in Britain ${ }^{20}$; however, about half of all affected children have additional serious non-ophthalmic impairments or chronic disorders and visual loss impacts on all aspects of the child's life. Thus, multidimensional care is required, provided by a wide range of professionals at different levels within the health service. ${ }^{20-22}$ Although most visually impairing childhood disorders in Britain are present from infancy, there may be a prolonged period of uncertainty before the final diagnosis is achieved: ophthalmic assessment of young children being difficult and the prognosis for vision for a given child depending on visual development as well as on the natural history of the disorder and the impact of any treatment available for it. These factors may partly account for the main parental criticisms in this study-provision of information and coordinated and comprehensive care. Equally, they may explain the notable observation of lower overall satisfaction reported by parents of children with more severe visual loss and those with multiple impairments, highlighting the subset of families with the greatest unmet needs.
The mean MPOC scores in the present study are comparable to those reported in studies of a range of other childhood impairments or disorders, ${ }^{10} 121323$ in which provision of general information is invariably consistently the lowest scoring domain. This is consistent with the great importance to parents of information about the broader aspects of accessing services and care for their child, irrespective of the precise nature of the impairment. In our study, the MPOC scores for information provision were lower for mothers than fathers and were consistent with needs expressed in the interviews. These findings concur with a previous report of variations in MPOC scores by $\operatorname{sex}^{23}$ and also with other studies $^{24} 25$ showing that mothers of young children with disabilities express significantly greater needs, including for information, than fathers. We suggest this reflects differences in roles rather than true differences by sex: mothers are usually the main carer and attend hospital appointments and use other services more often, and thus have more detailed information needs.

Children from some ethnic minorities, in particular Pakistani and Bangladeshi groups, are over-represented among children with visual impairment in Britain. ${ }^{26}$ Use of health services by children is known to vary by ethnicity and social $\operatorname{class}^{27} 28$ and may reflect differences in the degree to which parents from different ethnic groups are able to navigate successfully through the healthcare system. It is therefore an unexpected finding that MPOC scores for information provision were higher for parents from ethnic minorities than for white parents in our study. This may be explained by the qualitative data indicating that parents from ethnic minorities searched less actively for sources of information outside the hospital and relied mainly on their consultant ophthalmologist for it, than did white parents. This is consistent with previous reports of ethnic variations in information seeking by parents of children with disabilities. ${ }^{29}$ It is also unexpected to find that MPOC scores for enabling and partnership and coordinated and comprehensive care were higher for parents from ethnic minority groups. We suggest these findings, taken together, reflect sociocultural differences in expectations of health services and professionals regarding both information provision and the degree to which parents should be treated as equal partners in the care of their child, as well as sociocultural variations in parental accessing of health information directly. Such variations need to be addressed if health services are to be comprehensively family orientated.

Despite their criticisms of information giving, parents in this study reported high overall satisfaction with services. This supports previous reports linking satisfaction most closely with the structure and organisation of services and with the conduct of managing clinicians. ${ }^{15}$ Parents tend to identify information as their greatest need, ${ }^{29-33}$ almost irrespective of the amount or type actually provided. This is partly because their needs change over time, as their child grows and new issues arise, and partly because of their inherent uncertainty about their child's future and how best to prepare for it. ${ }^{19}$ Nevertheless, improving the medium, content, and scope of general information provided by professionals to parents of visually impaired children emerges as a priority. Remembering that informational and other needs vary by the parent's role (primary carer or not) and their ethnicity, as well as by the severity and complexity of their child's visual loss, should help to improve the ability to provide high quality health services for all families with children with visual impairment.

\section{ACKNOWLEDGEMENTS}

We are grateful to all parents who took part and Mr Kariofillis Zervoulis who contributed to data collection and analysis. We thank 
Professor David Taylor, Professor Catherine Peckham, Professor Alistair Fielder, and Dr Margaret Yerbury, who together comprised the study advisory group, for their helpful comments and discussions throughout its progress. This study was funded by a Health Services Project Grant from the Wellcome Trust.

The authors have no competing interests and confirm that ethics committee approval was secured for the study reported.

\section{Authors' affiliations}

J S Rahi, Centre for Paediatric Epidemiology and Biostatistics, and Department of Ophthalmology/Visual Sciences Unit, Institute of Child Health, Great Ormond Street Hospital, and the Department of Epidemiology, Institute of Ophthalmology, London, UK

I Manaras, Institute of Child Health, London, UK

H Tuomainen, School of Health and Social Studies University of Warwick, UK

G Lewando Hundt, Institute of Health, School of Health and Social Studies University of Warwick, UK

\section{REFERENCES}

1 Jan JE, Freeman RD. Who is a visually impaired child? Dev Med Child Neurol 1998;40:65-7.

2 Read J. Disability, the family and society. Listening to mothers, 1 st ed. Buckingham, UK: Open University Press, 2000.

3 Campbell D, Fiske D. Convergent and discriminant validation by the multitrait multimethods matrix. Psychol Bull 1959;56:81-105

4 Crawford MJ, Rutter D, Manley, et al. Systematic review of involving patients in the planning and development of health care. BMJ 2002;325:1263-5.

5 National Service Framework External Working Group on Disabled Children, (www.doh.gov.uk/nsf/children/externalwgdisabled.htm), 2003.

6 Rahi JS, Manaras I, Tuomainen H, et al. Engaging families in health servcies research on childhood visual impairment: barriers to, and degree and nature if bias in, participation. Br J Ophthalmol 2004;88:782-7.

7 King GA, Rosenbaum P, King SM. Evaluating family-centre service using a measure of parents' perceptions. Child Care Health Dev 1996;23:47-62.

8 King SM, Rosenbaum P, King GA. Parents' perceptions of caregiving: development and validation of a measure of processes. Dev Med Child Neurol 1996:38:757-72

9 Swaine BR, Pless IB, Friedmann DS, et al. Using the measure of processes of care with parents of children hospitalisedd for head injury. Am J Phys Med Rehab 1999:78:323-9.

10 O'Neil ME, Palisano RJ, Westcott SL. Relationship of therapists' attitudes, children's motor ability, and parenting stress to mothers' perceptions of therapists' behaviors during early intervention. Phys Ther 2001;81:1412-24.

11 Williams B. Patient satisfaction: a valid concept? Soc Sci Med 1994;38:509-16.

12 King G, Law M, King S, et al. Parents and service providers perceptions of the family-centredness of childrens rehabilitation services. Physical and Occupational Therapy in Pediatrics 1998;18:21-39.
13 Larsson M. Organising habilitation services: team structures and family participation. Child Care Health Dev 2000;26:501-14.

14 Larsen DL, Attkisson CC, Hargreaves WA, et al. Assessment of client/patient satisfaction: development of a general scale. Evaluation and Programme Planning 1979;2:197-207.

15 Krahn G, Eisert D, Fifield B. Obtaining parental perceptions of the quality of services for children with special needs. J Pediatr Psychol 1990;15:761-74.

16 Office for National Statistics. Birth statistics 2000. Series FMI no 29. London: The Stationery Office, 2000.

17 Office for National Statistics. (www.statistics.gov.uk/census 2001/pdfs/ H1.pdf) 2002.

18 Office for National Statistics. Standard occupational classification. London: The Stationery Office, 2000

19 Nixon HL. Mainstreaming and the American Dream. Sociological perspectives on coping with blind and visually impaired children. New York: American Foundation for the Blind, 1991.

20 Streiner DL, Norman GR. Health measurement scales. A practical guide to their development and use, 2nd ed. Oxford: Oxford University Press, 1995.

21 Tabachnick BG, Fidell LS. Using multivariate statistics, 4th ed. Boston: Allyn and Bacon, 2001.

22 Ireys HT, Perry JJ. Development and evaluation of a satisfaction scale for parents of children with special health care needs. Pediatrics 1999; 104:1182-91.

23 King GA, King SM, Rosenbaum P. How mothers and fathers view professional caregiving for children with disabilities. Dev Med Child Neurol 1996;38:397-407.

24 Bailey DB, Blasco PM, Simeonsson RJ. Needs expressed by mothers and fathers of young children with disabilities. Am J Mental Retardation 1992:97:1-10.

25 Gowen JW, Schoen Christy D, Sparling J. Informational needs of parents of young children with special needs. J Early Intervention 1993;17:194-210.

26 Rahi JS, Cable N, on behalf of the British Childhood Visual Impairment Study Group (BCVISG). Severe visual impairment and blindness in children in the UK. Lancet 2003:362:1359-65.

27 Saxena S, Eliahoo J, Majeed A. Socioeconomic and ethnic differences in selfreported health status and use of health services by children and young people in England: cross sectional study. BMJ 2002;325:520-3.

28 Cooper H, Smaje C, Arber S. Use of health services by children and young people according to ethnicity and social class: secondary analysis of a nation survey. BMJ 1998;317:1047-51

29 Sontag JC, Schacht R. An ethnic comparison of parent participation and information needs in early intervention. Exceptional Children 1994;60:422-33.

30 Sloper P, Turner S. Service needs of families of chlidren with severe physical disability. Child Care Health Dev 1992;18:259-82

31 Milner J, Bungay C, Jellinek D, et al. Needs of disabled children and their families. Arch Dis Child 1996;75:399-404.

32 Marchettti F, Bonati M, Marfisi RM, et al. Parental and primary care physicians' view on the managment of chrmic diseases: a study in Italy. Acta Paediatr 1995;84:1165-72.

33 Stallard $\mathbf{P}$, Lenton $\mathrm{S}$. How satisfied are parents of pre-school children who have special needs with the services they have received? A consumer survey. Child Care Health Dev 1992;18:197-205.

34 Townsend $\mathbf{P}$. Health and deprivation: inequalities and the north. London: Croom Helm, 1988 